\title{
Research Paper: The Prevalence of Internet Addiction and Its Associated Factors Among Iranian Adults
}

\author{
Saeed Yarahmadi ${ }^{1}$ (D) Fatemeh Zarei ${ }^{* *}$ (i), Afsaneh Sadooghiasl ${ }^{3}$ (i), Sookyung Jeong ${ }^{4}$ (i)
}

1. Department of Health Education, School of Public Health, Zanjan University of Medical Sciences, Zanjan, Iran

2. Department Health Education, Faculty of Medical Sciences, Tarbiat Modares University, Tehran, Iran.

3. Department of Nursing Education, Faculty of Medical Sciences, Tarbiat Modares University, Tehran, Iran.

4. Department of Nursing, Wonkwang University, Iksan City, Jeonbuk, South Korea.

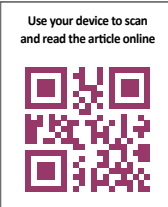

Citation: Yarahmadi S, Zarei F, Sadooghiasl A, Jeong S. The Prevalence of Internet Addiction and Its Associated Factors Among Iranian Adults. Iranian Rehabilitation Journal. 2020; 18(2):163-170. http://dx.doi.org/10.32598/irj.18.2.934.1

doi http://dx.doi.org/10.32598/irj.18.2.934.1

Article info:

Received: 10 Jan 2020

Accepted: 25 Apr 2020

Available Online: 01 Jun 2020

Keywords:

Addiction, Internet

addiction, Prevalence

\section{A B S T RACT}

Objectives: The internet is known as an essential part of individuals' daily life. The present descriptive research aimed to determine the prevalence rate of Internet Addiction (IA) and its related factors in Iran.

Methods: In total, 1046 internet users were recruited by a convenience sampling approach. The required data were collected by an online questionnaire, including a sociodemographic data scale and the Persian version of the Internet Addiction test. The obtained data were analyzed using SPSS

Results: The current study findings indicated that the prevalence rate of IA was equal to $57.6 \%$. The highest prevalence rate belonged to the research participants aged $\leq 35$ years $(67.5 \%)$, followed by females $(61.5 \%)$, married subjects $(66.7 \%)$, the holders of $\mathrm{MSc}$ and $\mathrm{PhD}$. degrees (65.8\%), and those employed in public sectors (68.5\%). The highest prevalence of IA was detected among the study participants who spent one hour daily on the internet $(94.7 \%)$; however, the lowest prevalence of the IA was observed among those who spent $>10$ hours daily on the internet (16.4\%). Moreover, there was no dramatic difference between the internet access source and the IA among the research participants $(\mathrm{P}>0.05)$. There was a significant relationship between all determined variables and the level of IA $(\mathrm{P}<0.05)$.

Discussion: The prevalence of IA was increasing in the studied population. Health educators are recommended to emphasize improving society's awareness of IA. They are also suggested to develop educational preventive measures on increasing media health literacy approaches. 


\section{Highlights}

- The prevalence of internet addiction was calculated as 57.6\% among the explored Iranian adults.

- The highest prevalence rate of internet addiction belonged to those aged $\leq 35$ years.

\section{Plain Language Summary}

A behavior disorder in the modern world is internet addiction. Most of the recent studies reported that internet addiction is common among adolescents. We assessed whether Iranian adults are addicted to the internet or not, and which characteristics of them related to their addiction. This study revealed that internet addiction is prevalent among adults, as well. This study also suggested increasing awareness about the outcomes of internet addiction in all aspects of real life.

\section{Introduction}

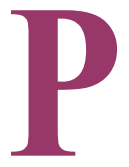

hysical inactivity, machinery life, and the overuse (overload) of cyberspace are the leading causes of disability and numerous problems in today's world. Accordingly, they impose great cost and energy on individuals for rehabilitation. With the advent of the internet, one of the new and widespread problems of today's society is the dependence on the internet [1]. As the development of information technology has grown remarkably, internet use has increased exponentially via computers and mobile phones. In 2016, the global number of internet users was estimated at around 3.4 billion [2]. The internet use is an unavoidable part of daily life. Individuals use the internet for different purposes, including learning, academic and research programs, the exchange of information, social communications, commerce, and entertainment.

Internet Addiction (IA) is described as compulsive internet use, with insufficient control over the material consumed and the time spent online [3]. Several studies indicated that IA correlates with various conditions, such as substance abuse, attention-deficient hyperactivity disorder, depression, social anxiety disorder, and interpersonal relationship problems [4]. Moreover, gender, educational level, financial status, and age are recognized as risk factors for IA among adults [5].

Unlike other types of addiction, IA cannot be easily observed. This is because all age groups can freely access the internet and there is no third-party supervision. Therefore, it is crucial to determine the prevalence rate of IA and identify its risk factors among adults.

A 2018 study by the Pew Research Center demonstrates that the proportion of web usage among adolescents has risen dramatically since their previous study in 2000 , with a usage rate of $97 \%-98 \%$ for adolescents aged 18 to 49 years [6]. Additionally, IA rates increased in adults in some countries from $2 \%$ to $22.8 \%$ [7-10]; it has emerged as a rapidly growing problem and attracted global attention [11].

Iranians have accessed the internet since 1992, and there has been a rapid increase in the frequency of internet users. Iran is currently ranked first on internet use in the Middle East [12]. An IA problem is possible among Iranian adults; however, previous studies mainly targeted adolescents or university students in this area [13]. Besides, few studies explored IA among Iranian adults. Therefore, this study aimed to determine the prevalence rate and risk factors of IA among Iranian adults.

Recent statistics by the Ministry of Information and Communications Technology of Iran up to September 2017 indicated that Iran's number of mobile internet users has reached 47 million individuals. The past statistics of June 2017 were 41 million users. More than 10 million and 490000 Iranians are internet landline subscribers using Asymmetric Digital Subscriber Line (ADSL) or fiber optic facilities. There has been little growth in the number of landline internet customers since June 2017; however, the number of mobile internet users has grown to 41 million over 6 million in the same period. Currently, all Iranian mobile operators have access to $3 \mathrm{G}$ and $4 \mathrm{G}$ internet $[12,14]$.

The penetration rate of mobile subscribers in Iran has grown 2.5 times since 10 years ago. The present penetration rate in Iran for active mobile users is $106.43 \%$, while the same figure was only $39.5 \%$ in 2007, 12 years earlier. By the end of September 2017, Iranians have been allocated 156 million and 548000 SIM cards, of which, 85 million and 64000 are active. Internet speed in Iran improved in the first quarter of 2017 from $4135.53 \mathrm{KBps}$ in the fourth quarter of 2016 to $4703.97 \mathrm{KBps}$ [12]. 


\section{Methods}

This descriptive research was conducted in Iran, in 2017. Iran, with a population of 81 million and latitude of $1648195 \mathrm{~km} 2$, is the 18 th most populous and 17 th largest country in the world. Besides, 56.7 million Iranians have access to the internet.

Our study sample included individuals who had access to the questionnaire link through social networks.

The study inclusion criteria were as follows: having access to the internet, willingness to participate in the survey, and completing the online questionnaire. The study participants were recruited by convenience and network sampling methods.

The following tools were used as a self-administered questionnaire:

The sociodemographic questionnaire: It consisted of items on age, gender, marital status, educational status, occupationa 1 status, having access to the internet, and spending time on the internet.

Internet Addiction Test (IAT): Young (1998) originally developed IAT to measure IA levels [15]. The original questionnaire was in English. We used its Persian version in this study [16]. The IAT consists of 20 items classified on a five-point Likert-type scale, including: 1 . Rarely: 2. Occasionally; 3. Frequently; 4. Often; 5. always. The total scoring ranged from 20 to 100 , in which scores 20-49 were interpreted as 'normal', scores 50-79 indicated 'being exposed to addiction', and scores 80 100 reflected 'addiction'. The content validity and internal consistency reliability of the IAT were approved in a prior study (Cronbach's alpha coefficient $=0.88$ ) [17].

An Informed consent statement was included in the questionnaire guidelines and participation in this study was voluntary. The study participants were provided with detailed information about the aims, methods, and data collection approach of the present study. The confidentiality and anonymity of participants were also ensured. Consent was implied with completing the questionnaire. The research participants expressed their agreements by completing the anonymous online form, individually.

Initially, we created an online format for both study questionnaires. Then, we sent the questionnaire link through social networks (nationally \& internationally) to online individuals. The questionnaire had a guideline that explained the aims and methods of the study and in- cluded the informed consent statement. We requested the research participants to provide the questionnaire link to their available contacts. Social national and international networks, including Telegram, Integral, and WhatsApp were used. Participation in this study was voluntary and anonymous. Every research participant was allowed to complete only one questionnaire.

We used SPSS for data management and analysis. Descriptive statistics, including frequency, mean, and standard deviation, as well as analytical statistics, including the Chi-squared test were used for data analysis. P0.05 was considered as the level of significance.

\section{Results}

The total number of adults taking part in the study was $1046 ; 405(38.7 \%)$ of whom were male and $641(61.3 \%)$ were female. The Mean \pm SD age of the research participants was $33 \pm 1.16$ years. The research participants were distributed nearly equally across all levels of education. About half (47.6\%) of them reported their marital status as single. In terms of occupation, a quarter of them were students. Moreover, about $40 \%$ of the explored participants were employed, while the rest of them were freelancers. The sources of internet access, as reported by the study participants, were Wi-Fi data and cellular data (41.5\%). Approximately $72 \%$ of the study subjects used the internet for 1-6 hours daily (Table 1). As revealed in Table 2, 602 (57.6\%) of the study participants fell in the IA status, while $82(7.8 \%)$ of them were placed in the 'normal' category of IA

The study participants below 35 years of age shaped the highest IA prevalence rate $(67.5 \%)$. Females had a higher proportion of IA than males ( $61.5 \%$ vs. $51.4 \%)$. The lowest IA prevalence among respondents holding MSc and Ph.D. was $65.8 \%$. Married respondents had a greater proportion of IA, compared to the single participants $(66.7 \%$ vs. 52\%). The highest prevalence rate of IA among respondents in the public sector was $68.5 \%$. The highest prevalence rate of IA among respondents who spent 1 hour a day on the internet equaled $94.7 \%$; however, the lowest prevalence rate of IA among the respondents who spent more than 10 hours a day on the internet was measured as $16.4 \%$. In addition, there was no significant distinction between the respondents concerning IA and the internet access source. The connection between all factors and the IA level was significant (Table 3).

Table 4 describes the relationship between IA and its associated risk factors. The findings of Pearson's correlation indicated a significant and positive relation- 
Table 1. The study participants' characteristics ( $N=1046)$

\begin{tabular}{|c|c|c|}
\hline Variables & Characteristics & No. (\%) \\
\hline \multirow{4}{*}{ Age (y) } & $20-25$ & $332(31.7)$ \\
\hline & $26-30$ & $242(23.1)$ \\
\hline & $31-35$ & 195 (18.6) \\
\hline & $>35$ & $277(26.5)$ \\
\hline \multirow{2}{*}{ Gender } & Male & 405 (38.7) \\
\hline & Female & $641(61.3)$ \\
\hline \multirow{4}{*}{ Educational level } & High school & $156(14.9)$ \\
\hline & Some college or technical school degree & 115 11.0) \\
\hline & BA & $474(45.3)$ \\
\hline & MSc. \& PhD. & $301(28.8)$ \\
\hline \multirow{3}{*}{ Marital status } & Single & $498(47.6)$ \\
\hline & Married & $465(44.5)$ \\
\hline & Divorced & $83(7.9)$ \\
\hline \multirow{5}{*}{ Average hours of daily internet usage } & $<1$ & $76(7.3)$ \\
\hline & $1-2$ & $403(38.5)$ \\
\hline & $3-6$ & $347(33.2)$ \\
\hline & $6-10$ & $153(14.6)$ \\
\hline & $>10$ & $67(6.4)$ \\
\hline
\end{tabular}

ship between IA, age $(\mathrm{r}=0.139 ; \mathrm{P}<0.001)$, educational level ( $\mathrm{r}=0.091 ; \mathrm{P}=0.003)$, and demographic characteristics. Internet usage patterns were significantly correlated with IA. Negative relationships existed between IA and average daily internet use hours $(\mathrm{r}=-0.456 ; \mathrm{P}<0.001)$.

\section{Discussion}

The current study investigated the prevalence rate and associated factors of IA in an online survey sample, representing the general Iranian population (aged $\geq 20$ years). The latest analysis of the accessible literature on IA from the Mediterranean region revealed that previous epidemiological studies only included adolescents or students as a key target group $[18,19]$. Therefore, our study's main strength was its population-based cross-sectional online survey design that covered various age groups beyond adolescence and school age. The significant weakness of the study was the lack of opportunity to adjust the sample to design the online survey for variations in gender, age group, and residence place.

In our study's population, nearly $58.0 \%$ of the investigated participants were classified as addicted to the internet. This proportion is consistent with a prior Mediterranean study. While findings are not immediately similar due to variations in diagnostic requirements, it appears likely that domestic and global nations have observed a greater incidence in this regard [18].

Studied on the prevalence of IA are difficult to compare due to differences in internet access level in the studied populations, variations in respondent recruitment, implementing different methodologies, including diagnostic tools, differences in age groups included, sampling techniques, cultural variations amongst populations even within the same nation, and differences in the sets of employed inclusion criteria.

Table 2. The status of IA among the investigated adolescents ( $\mathrm{N}=1046)$

\begin{tabular}{cc}
\hline Status of IA & No. (\%) \\
\hline $1.00=$ Non-problematic & $82(7.8)$ \\
\hline $2.00=$ At risk for addiction & $362(34.6)$ \\
$3.00=$ Addicted & $602(57.6)$ \\
\hline
\end{tabular}

Mranian Rehabilitation Journal 
Table 3. The prevalence rate of IA among the studied adolescents $(\mathrm{N}=1046)$

\begin{tabular}{|c|c|c|c|c|}
\hline \multirow{2}{*}{\multicolumn{2}{|c|}{ Variables }} & \multicolumn{3}{|c|}{ No. (\%) } \\
\hline & & $1=$ Normal & 2= Exposed to Addiction & 3= Addiction \\
\hline \multirow{5}{*}{ Age (y) } & $20-25$ & $29(8.7)$ & $138(41.6)$ & $165(49.7)$ \\
\hline & $26-30$ & $25(10.3)$ & $82(33.9)$ & $135(55.8)$ \\
\hline & $31-35$ & $18(9.2)$ & $62(31.8)$ & $115(59.0)$ \\
\hline & $>35$ & $10(3.6)$ & $80(28.9)$ & $187(67.5)$ \\
\hline & & & 01 & \\
\hline \multirow{3}{*}{ Gender } & Male & $36(8.9)$ & $161(39.8)$ & $208(51.4)$ \\
\hline & Female & $46(7.2)$ & 201 (31.4) & $394(61.5)$ \\
\hline & & & 006 & \\
\hline \multirow{5}{*}{ Education } & High school & $12(7.7)$ & $58(37.2)$ & $86(55.1)$ \\
\hline & $\begin{array}{l}\text { Some college or technical } \\
\text { School }\end{array}$ & $15(13.0)$ & $42(36.5)$ & $58(50.4)$ \\
\hline & Bachelor & $34(7.2)$ & $180(38.0)$ & $260(54.9)$ \\
\hline & MSc. and PhD. & $21(7.0)$ & $82(27.2)$ & $198(65.8)$ \\
\hline & & & & \\
\hline \multirow{4}{*}{ Marital Status } & Single & $42(8.4)$ & 197 (39.6) & $259(52.0)$ \\
\hline & Married & $27(5.8)$ & $128(27.5)$ & $310(66.7)$ \\
\hline & Divorced & $13(15.7)$ & $37(44.6)$ & $33(39.8)$ \\
\hline & & & & \\
\hline \multirow{6}{*}{$\begin{array}{l}\text { Average hours of daily } \\
\text { internet usage }\end{array}$} & $<1 \mathrm{~h}$ & $0(0.0)$ & $4(5.3)$ & $72(94.7)$ \\
\hline & $1-3 h$ & $13(3.2)$ & $85(21.1)$ & 305 (75.7) \\
\hline & $>3-6 h$ & $20(5.8)$ & $158(45.5)$ & $169(48.7)$ \\
\hline & $>6-10 \mathrm{~h}$ & $23(15.0)$ & $85(55.6)$ & $45(29.4)$ \\
\hline & $>10 \mathrm{~h}$ & $26(38.8)$ & $30(44.8)$ & $11(16.4)$ \\
\hline & \multicolumn{4}{|c|}{$P<0.001$} \\
\hline
\end{tabular}

Iranian Rehabilitation Journal

Table 4. The relationship between demographic characteristics, internet usage patterns, and IA

\begin{tabular}{ccc}
\hline Risk Factors & $\mathbf{r}$ & $\mathbf{P}$ \\
\hline Age $(\mathrm{y})$ & 0.139 & $<0.001^{* *}$ \\
\hline Educational level & 0.091 & $0.003^{* *}$ \\
Average hours of daily internet usage & -0.456 & $<0.001^{* *}$ \\
\hline
\end{tabular}

** Significant at <0.01 (2-tailed)

Iranian Rehabilitation Journa

To compare previous studies, the probable reasons for a higher level of IA might be related to internet use, broadband, and telecommunications in Iran. According to Internet World Stats (IWS), approximately $70.0 \%$ of the population (56700000 persons) were recognized as internet users on Dec. 31, 2017 [14]. Moreover, the socio-cultural characteristics of Iranian society is another reason in this area. There are no nationally defined regulations or policies for limiting cyber behaviors for internet users.
A present research finding was that IA prevalence changed with age. Furthermore, there was a high prevalence of IA among the study participants aged $\geq 35$ years $(67.5 \%)$. This result suggests that this group is much more disposed than other age groups to excessive internet use. The higher level of IA in the research participants aged $\geq 35$ years may be related to the Iranians' sociocultural characteristics. Iranian families are conservative and have some control and supervision over their children and teenagers' cyber behaviors in the school age. However, this finding was inconsistent with 
recent studies, indicating a high prevalence of IA among students aged 15 years $[11,18]$.

This study demonstrated that the prevalence of IA varies between gender categories. Females formed a higher frequency of IA than males (61.5\% vs. $51.4 \%)$. The obtained data correspond to an earlier study [18] which reported that IA had higher rates in females than males; however, these data were inconsistent with other findings [20] suggesting that males had a higher probability of IA than females. In terms of IA, Koyuncu et al. (2014) indicated no gender-wise differences. Apart from the total number of adults who participated in this study, $641(61.3 \%)$ individuals were female. The most believed interpretation of this finding is that adult females use the internet more, i.e. because they are more concerned about personality. There is evidence that adult females present information-seeking behaviors by searching different health-related websites [21], building social networking, making close friends, and exchanging sensitive feelings and ideas with males.

The achieved study results indicated that adults with university degrees or higher education have higher internet access, compared to the other groups. According to Aslanidou and Menexes, social and educational levels, as health indicators, are linked to internet accessibility [22]. However, the highest prevalence rate of IA among the research participants holding MSc and Ph.D. degrees was calculated as $65.8 \%$. This result is consistent with similar studies in the assumption that high-education internet-addicted users registered a wider range of internet activities, compared to non-problematic users [23]. Purposes, such as taking part in academic activities, searching for information, purchases, and order of goods and services, and communications are common activities among highly-educated users.

The present study revealed that the majority of the investigated adults reported 1-3 h of daily internet use. Besides, few research participants reported more than $10 \mathrm{~h}$ of daily internet use. This finding is consistent with those revealed by Malake [18]. Some studies revealed a positive correlation between the duration of internet use and the odds of developing IA [23]. Not surprisingly, their data revealed that internet-addicted individuals spend more time on the internet than the healthy population. Most specifically, the internet use duration is an indicator of IA, according to Czincz and Hechanova.

The present research results indicated that Iranian married internet users appeared to shape a higher proportion of internet addiction, compared to single internet users
(66.7\% vs. 52\%). Nevertheless, such a relationship was found in most of the previous studies which found that IA was more frequent among single subjects, rather than the married ones [23, 24].

This study had some limitations. Presenting an online survey about IA in online participants using internet warnings was a study limitation; thus, such results must be viewed with caution. However, the present study data highlight the importance of developing and implementing preventive interventions concerning IA among adolescents. Furthermore, educational programs are suggested to raise the awareness of individuals with IA and improve their perceptions of changing behaviors about IA, as a problem. Future studies are required to focus on educational intervention programs in the preventive perspective in all ecological groups, organizations, communities, and policy-based intervention levels. Rich awareness and positive attitudes about IA among all internet users (from school students to adults) are the concerns of public health. The healthcare team, particularly health education professionals, should develop preventive educational programs to increase individuals' health media literacy about IA. Informational camping programs are effective in this respect. Moreover, it is necessary to design screening programs in healthcare centers for monitoring and managing IA among high-risk populations.

\section{Conclusion}

Overall, this study highlighted the increasing IA prevalence and its associated factors among the Iranian population. The obtained data revealed that $58 \%$ of the study participants presented IA. The related factors of IA were age, gender, educational level, the average hours of daily internet use, and marital status.

\section{Ethical Considerations}

\section{Compliance with ethical guidelines}

All stages of this study were conducted according to the Ethics Committee of Zanjan University of Medical Sciences (Code: ZUMS.REC.1395.299).

\section{Funding}

The present paper was extracted from the MSc. thesis of the first author at the Department of Health Education, School of Public Health, Zanjan University of Medical Sciences. 


\section{Authors' contributions}

Methodology, funding acquisition: Fatemeh Zarei, Saeed Yarahmadi; Investigation: Saeed Yarahmadi; Writing-original draft: Fatemeh Zarei, Afsaneh Sadooghiasl; Writing-review \& editing: Fatemeh Zarei, Afsaneh Sadooghiasl, Sookyung Jeong; Supervision: Fatemeh Zarei.

\section{Conflict of interest}

The authors declared no conflicts of interest.

\section{Acknowledgments}

The authors would like to thanks to Zanjan University of Medical Sciences for supporting this research.

\section{References}

[1] Griffiths M. Internet addiction-time to be taken seriously? Addiction Research. 2000; 8(5):413-8. [DOI:10.3109/16066350009005587]

[2] International Telecommunication Union. Measuring the information society report [Internet]. 2016 [Updated 2016]. Available from: https:/ / www.itu.int/en/ITU-D/Statistics / Documents/publications/misr2016/MISR2016-w4.pdf

[3] Spada MM. An overview of problematic internet use Addictive Behaviors. 2014; 39(1):3-6. [DOI:10.1016/j.addbeh.2013.09.007] [PMID]

[4] Rezayi S, Massah O. Internet dependence and sensation seeking in youth with moderate cerebral palsy. Iranian Rehabilitation Journal. 2017; 15(2):95-102. [DOI:10.18869/nrip. irj.15.2.95]

[5] Anderson EL, Steen E, Stavropoulos V. Internet use and problematic Internet use: A systematic review of longitudinal research trends in adolescence and emergent adulthood. International Journal of Adolescence and Youth. 2017; 22(4):430-54. [DOI:10.1080/02673843.2016.1227716]

[6] Pew Research Center. Internet use by age [Internet]. 2017 [Updated 2017 Jan 11]. Available from: http:/ / www.pewinternet.org/chart/internet-use-by-age/

[7] Canan F, Ataoglu A, Ozcetin A, Icmeli C. The association between Internet addiction and dissociation among Turkish college students. Comprehensive Psychiatry. 2012; 53(5):4226. [DOI:10.1016/j.comppsych.2011.08.006] [PMID]

[8] J Kuss DJ, D Griffiths MD, Karila L, Billieux J. Internet addiction: A systematic review of epidemiological research for the last decade. Current Pharmaceutical Design. 2014; 20(25):4026-52. [DOI:10.2174/13816128113199990617] [PMID]
[9] Király O, Urbán R, Griffiths MD, Ágoston C, Nagygyörgy K, Kökönyei $\mathrm{G}$, et al. The mediating effect of gaming motivation between psychiatric symptoms and problematic online gaming: An online survey. Journal of Medical Internet Research 2015; 17(4):e88. [DOI:10.2196/jmir.3515] [PMID] [PMCID]

[10] Krishnamurthy Sh, ChetlapalliSK. Internet addiction: Prevalence and risk factors: A cross-sectional study among college students in Bengaluru, the Silicon Valley of India. Indian Journal of Public Health. 2015; 59(2):115-21. [DOI:10.4103/0019557X.157531] [PMID]

[11] Wu CST, Wong HT, Yu KF, Fok KW, Yeung SM, Lam CH, et al. Parenting approaches, family functionality, and Internet addiction among Hong Kong adolescents. BMC Pediatrics. 2016; 16:130. [DOI:10.1186/s12887-016-0666-y] [PMID] [PMCID]

[12] Iran Communications Technology Ministry (ICTM). Exact measure of Internet user's number at a glance [Internet] 2010 [Updated 2010 May 05]. Available from: https://www. ict.gov.ir/en/news/4529/Exact-measure-of-Internet-user-snumber-at-a-glance

[13] Langarizadeh M, Naghipour M, Tabatabaei SM, Mirzaei A, Eslami Vaghar M. Prediction of Internet addiction based on information literacy among students of Iran University of Medical Sciences. Electronic Physician. 2018; 10(2):6333-40. [DOI:10.19082/6333] [PMID] [PMCID]

[14] Internet World Stats. Iran Internet usage, broadband and telecommunications reports [Internet]. 2017 [Updated 2017 Dec 31]. Available from: https://internetworldstats.com/ me/ir.htm

[15] Young KS. Internet addiction: The emergence of a new clinical disorder. Cyberpsychology \& Behavior. 1998; 1(3):237-44. [DOI:10.1089/cpb.1998.1.237]

[16] Bahri N, SadeghMoghadam L, Khodadost L, Mohammadzade J, Banafsheh E. [Internet addiction status and its relation with students' general health at Gonabad Medical University (Persian)]. Modern Care, Scientific Quarterly of Birjand Nursing and Midwifery Faculty. 2011; 8(3):166-73. http://bsid.bums.ac.ir/dspace/handle/bums/5250

[17] Ghasemzadeh L, Shahrarai M, Moradi AR. [The extent of internet addiction and its relation to loneliness and self esteem among Tehran high school students (Persian)]. Journal of Education. 2007; 23(1):41-68. http://ensani.ir/fa/article/168483/

[18] Malak MZ, Khalifeh AH, Shuhaiber AH. Prevalence of Internet addiction and associated risk factors in Jordanian school students. Computers in Human Behavior. 2017; 70:556-63. [DOI:10.1016/j.chb.2017.01.011]

[19] Mohammadkhani P, Alkasir E, Pourshahbaz A, Jafarian Dehkordi F, Soleimani Sefat E. Internet addiction in high school students and its relationship with the symptoms of mental disorders. Iranian Rehabilitation Journal. 2017 15(2):141-8. [DOI:10.18869/nrip.irj.15.2.141]

[20] Vondráčková P, Gabrhelik R. Prevention of Internet addiction: A systematic review. Journal of Behavioral Addictions. 2016; 5(4):568-79. [DOI:10.1556/2006.5.2016.085] [PMID] [PMCID]

[21] Ek S. Gender differences in health information behaviour: A finnish population-based survey. Health Promotion International. 2015; 30(3):736-45. [DOI:10.1093/heapro/dat063] [PMID] 
[22] Aslanidou S, Menexes G. Youth and the Internet: Uses and practices in the home. Computers \& Education. 2008; 51(3):1375-91. [DOI:10.1016/j.compedu.2007.12.003]

[23] Salehi M, Norozi Khalili M, HojjatSK, Salehi M, Danesh A. Prevalence of Internet addiction and associated factors among medical students from Mashhad, Iran in 2013. Iranian Red Crescent Medical Journal. 2014; 16(5):e17256. [DOI:10.5812/ircmj.17256]

[24] Dargahi H, Razavi SM. [Internet addiction and its related factors: A study of an Iranian population (Persian)]. Payesh. 2007; 6(3):265-72. http:// payeshjournal.ir/article-1-705-en.html 